The Egyptian International Journal of Engineering Sciences \& Technology, Vol 4, No 1 (2000)

\title{
FUZZY LOGIC CONTROLLER FOR THE (ET-RR-1)
}

z.s ZselRazaz, A SalahEldin

\begin{abstract}
A fiizzy logic controUer (FLC) for ttie first Egyptian Research Reactor (ET-RR-I), is constructed.

The controller adjusts the rector power set point due to the seasonal temperature changes, which affect the average core temperature and initial start up positions of the automatic control rod. Also, it adjusts the setting due to any change in the primary coolant flows.
\end{abstract}

